\title{
A CONTENDA DE MAX HORKHEIMER CONTRA O PRAGMATISMO
}

\section{RODRIGO OLIVEIRA DE ARAÚJO ${ }^{1}$}

RESUMO: O presente artigo tem por finalidade apresentar, em linhas gerais, a crítica engendrada pelo filósofo alemão Max Horkheimer [1895-1973] ao pragmatismo norteamericano, especialmente aquele defendido por J. Dewey [1859-1952]. Pretende-se demonstrar a força, e, por vezes também, a fragilidade retórica do alemão, bem como o alcance crítico desta, especialmente no que diz respeito ao tópico epistemológico sobre o conhecimento. Em um primeiro momento apresentamos os pilares estruturantes do pragmatismo e da versão de Horkheimer sobre a razão; em seguida tratamos da maneira como Horkheimer enfrenta as posições do pragmatismo $_{2}$ associando-o a uma recente tradição moderna que abriu mão do uso objetivo da racionalidade em nome de uma subjetivação da mesma. Finalizamos este trabalho com uma apreciação do alcance discursivo de Horkheimer sobre a doutrina pragmática.

PALAVRAS-CHAVE: Pragmatismo, Teoria Crítica, Razão objetiva/subjetiva, Conhecimento.

ABSTRACT: The goal of the following article is to show, in general terms, the critic made by the German philosopher Max Horkheimer [1895-1973] to North-American pragmatism, especially the pragmatism as proposed by J. Dewey [1859-1952]. The intention is to show the strength and, sometimes, also the weakness on the German's rhetoric, as well as its critical reach, especially when concerning the epistemological topic. At first we present the pillars of pragmatism and Horkheimer's version of reason; after that, we engage the way Horkheimer faces pragmatist propositions and associate them to a recent modern tradition which let go of the objective rationality in favor of a subjectivation of it. At the end we assess the discursive reach of Horkheimer about pragmatic doctrine.

KEYWORDS: Pragmatism, Critical Theory, Reason objective/subjective, Knowledge.

$\mathrm{O}$ ataque realizado por Adorno e Horkheimer à racionalidade instrumentalizada parece ter marcado em definitivo o debate filosófico no decorrer do século XX. Empenhados em designar as contradições internas aos diversos usos a que a razão se prestou na história do ocidente, os dois realizam uma dura crítica à sociedade moderna que culmina no livro, já tornado clássico, Dialética do esclarecimento, escrito conjuntamente pelos autores em 1948. No entanto, as raízes dessa crítica já podem ser encontradas, programaticamente, em um conjunto de ensaios redigidos por Horkheimer intitulado Eclipse da razão, publicado em 1947. Neste trabalho de grande fôlego filosófico, o autor identifica dois sentidos, ou, se preferir, duas dimensões a que se dá o uso da razão (Vernunft), que ele chamará de subjetiva e 
objetiva, havendo, em nossa época, uma predominância do uso da primeira sobre a segunda. Tal predominância tem encontrado abrigo não somente na sociedade amplamente industrializada, mas também nas filosofias que, para o autor, representam esta mesma sociedade, sendo a filosofia de viés pragmático aquela que lhe é o_mais adequada porta-voz.

Foi C. S. Peirce, W. Jammes e J. Dewey que lançaram as bases do que se passou a chamar de corrente pragmática, uma filosofia que se desenvolveu no ambiente norte-americano e que encontrou nestes autores os seus principais expoentes. Mas é sobretudo contra Dewey, "cuja filosofia é a mais radical e consistente forma de pragmatismo" (HORKHEIMER, 2007, p. 53), que Horkheimer dirige a sua crítica mais severa. De uma maneira bastante apressada, podemos definir o pragmatismo como uma teoria que se filia a uma tradição epistemológica empirista, que se apresenta como método e tem na ação o seu fundamento. Horkheimer identifica um anti-intelectualismo nesta filosofia que torna, analogamente, impraticável compreendê-la em termos intelectuais. Embora se apresente no decorrer de sua obra como um dos mais fervorosos combatentes da tradição "racionalista", filiando-se a uma tradição contrária que passa por Nietzsche, Marx e Freud, o desenho crítico desenvolvido por Horkheimer, em Eclipse da razão, parece avizinhá-lo, justamente, a uma orientação filosófica que James chamou de "Espírito terno", em oposição ao "Espírito duro". Sobre a primeira podemos encontrar as seguintes características: racionalista (“que segue princípios"), intelectualista, idealista, otimista, religiosa, livre-arbitrista, monista e dogmatista; na segunda, o "Espírito duro", nota-se as seguintes características: empirismo (que segue fatos), sensacionalismo, materialismo, pessimismo, irreligiosidade, fatalismo, pluralismo e ceticismo $^{2}$. Susan Stebbing, em The Nature Of French Voluntaristic Philosophy ${ }^{3}$, irá retomar esta divisão numa formulação um pouco mais simples e direta, embora não menos complexa, tratando as duas tendências entre intuicionistas e voluntaristas. A nosso ver, Horkheimer, em Eclipse da razão, filia-se à primeira.

\section{As duas dimensões da razão}

Para Horkheimer, como afirmado anteriormente, a racionalidade humana é dotada de duas dimensões, a subjetiva e a objetiva. A dimensão subjetiva é a ação racional que classifica, infere e deduz, que se relaciona 
subjetiva] concede pouca importância à indagação de se os propósitos como tais são racionais. (HORKHEIMER, 2007, p. 9)

Já a dimensão objetiva da razão exprime não somente a força da mente individual, mas também do mundo objetivo, as relações entre os homens e classes sociais, entre os homens e as instituições, entre os homens e a natureza e as suas próprias manifestações. Foi esta a dimensão que, segundo o filósofo, predominou em grande parte dos sistemas filosóficos da tradição, tais como os de Platão, Aristóteles, Tomás de Aquino e Hegel. Foram sistemas que procuraram abranger a totalidade de "todos os seres, incluindo o homem e seus fins [e] o grau de racionalidade de uma vida humana podia ser determinado [para estes sistemas] segundo a harmonização com essa totalidade" (HORKHEIMER, 2007, p. 10). A estrutura objetiva determina a avaliação do pensamento e da ação individual e diz respeito ao destino de todos os seres, incluindo aí o homem. Se a dimensão subjetiva é aquela que utilizamos no manuseio de um instrumento, na aplicação de um saber, numa tecnologia, é importante que se diga que a dimensão objetiva não a exclui, mas apenas a considera como sendo uma expressão parcial e limitada de uma razão mais geral.

É necessário esclarecer que há, segundo o autor, uma interdependência das duas dimensões da razão, havendo em nós, afinal, exclusivamente uma única racionalidade. Sua crítica chama atenção à hipervalorização da dimensão subjetiva e do seu desdobramento no manuseio da técnica, culminando em um mundo cada vez mais controlado e centralizado. Entretanto, deve-se observar que não nos é possível prescindir dela, da dimensão subjetiva, já que é de fundamental importância para nosso estar no mundo. Diante da construção de uma usina de energia, eu não posso (ou ao menos não deveria) abrir mão da avaliação objetiva para verificar a sua validade ou invalidade ética para a comunidade a que ela se destina. Entretanto, sem a ação subjetiva da razão, eu não posso sequer presumir a existência da própria usina. Fica claro, pois, que não se trata de desqualificar este ou aquele uso da racionalidade, mas de destacar o uso demasiado de um sobre o outro, como é o caso do que indica a filosofia do pragmatismo.

\section{Crítica ao pragmatismo}

"Uma ideia, um conceito ou uma teoria nada mais são do que um esquema ou um plano de ação, e portanto a verdade é nada mais do que o sucesso da ideia" (HORKHEIMER, 2007, p.46). É com estas palavras que Horkheimer define, com boa dose de coerência, o cerne 
do pragmatismo, uma filosofia que presume que ideias verdadeiras são capazes de nos conduzir a zonas verbais e conceituais proveitosas, mas também à consumação de metas sensíveis úteis que culminam em zonas consistentes, estáveis e capazes de favorecer uma comunicação fluente. Para Dewey, a ideia é um projeto traçado sobre algo que existe e intenciona arranjar as coisas existentes em conformidade com certos interesses que se impõem. O êxito deste arranjo, ou seja, o seu sucesso, irá determinar a verdade ou falsidade da ideia, sua viabilidade ou inviabilidade e, nesse sentido, a ideia verdadeira é sempre fruto de uma urgência, de uma necessidade em maior ou menor grau que nos acomete em maior ou menor profusão. A verdade de uma ideia científica sobre a aplicação de uma vacina em uma população diante de uma epidemia poderá ser confrontada, simplesmente, com a eficácia ou ineficácia de seu uso, sendo, neste caso, a urgência da saúde e da vida que irá sustentar a verdade ou a falsidade desta ideia, ou seja, a verdade da ideia será instituída em conformidade com o êxito do projeto sobre as coisas existentes, neste caso, a epidemia. Uma filosofia assim confere um caráter provisório à verdade, chocando-se diretamente com uma tradição filosófica que pretende pensá-la numa perspectiva universal e eterna, atraindo esta filosofia para si uma série de críticas que procuram destituir o seu mérito filosófico.

Horkheimer, um dos principais algozes e detratores dessa tendência, chega a aproximar o pragmatismo a um positivismo de tipo comteano sem se dar ao trabalho de esclarecer o tipo de ligação que vincula uma tendência a outra, simplesmente apondo-as como filosofias que se identificam com o cientificismo que desconsideram o caráter objetivo da razão e, de certo modo, negligenciam a intuição filosófica num franco apelo antiintelectualista. Desse modo, o autor se sente tentado a

\footnotetext{
Negar qualquer pedigree filosófico a uma doutrina que sustenta não que nossas expectativas se realizam e que nossas ações são bem sucedidas porque nossas ideias são verdadeiras, mas o contrário, de que nossas ideias são verdadeiras porque nossas expectativas se cumprem e nossas ações têm sucesso (HORKHEIMER, 2007, p.47).
}

Para Horkheimer não se pode atribuir essa evolução das ideias a Kant, como quis Peirce, pois Kant fez a compreensão científica depender do transcendental, em tudo universal e a priori, e não das funções empíricas. Não houve em Kant uma liquidação da verdade com o propósito de identificá-la com as noções práticas de verificação, tampouco ensinou que significado e efeito são a mesma coisa. Pensar dessa forma seria tão estreito quanto reduzir o significado de qualquer ideia a um plano ou projeto. O que o pragmatismo realizou, desde os seus primórdios, foi uma justificativa da lógica da verdade pela lógica da probabilidade, "pois 
se um conceito ou uma ideia é significativo só por virtude das suas consequências, qualquer afirmação exprime uma expectativa com um grau mais alto ou mais baixo de probabilidade" (HORKHEIMER, 2007, p.46), conclui o alemão.

Para Horkheimer, assumir a filosofia como uma expressão cultural "com uma visão das possibilidades futuras com a indicação de que se alcance o melhor e se evite o pior", como pretenderam os pragmáticos, é avizinhá-la, ou senão reduzi-la, ao trabalho já realizado pelas ciências naturais, é transfigurá-la num mero discurso de probabilidades e cálculos, abrindo-se mão do clássico exercício filosófico de exame contemplativo da existência, conforme a razão objetiva é capaz de realizar. Mas é ainda preciso considerar aquilo que Horkheimer chama de uma "espécie de filosofia da previsão". Para o autor, existe um problema de consideração lógica nas formulações pragmáticas sobre o conhecimento, posto que não diferenciam entre os juízos de prognose, por assim dizer, daqueles apodíticos, ou seja, aqueles que são auto-evidentes e necessários. Um juízo como "Amanhã choverá" traz uma prognose, na medida em que suas consequências ainda estão por ser verificadas, mas existem juízos que podem ser verificados imediatamente após a sua formulação e que, portanto, são verdadeiros independentemente de suas consequências. Embora Horkheimer seja obscuro nesta passagem, pois se limita a oferecer exemplos sobre os juízos de prognose, poderíamos questionar sobre qual seria a natureza dos juízos auto-evidentes, ou apodíticos. Seriam também eles oriundos de uma demanda prática, de uma urgência natural ou frutos de um "intuicionismo" ou de um "eu profundo", como que saídos das profundezas da terra ou caídos do céu? Ao criticar a epistemologia do pragmatismo, Horkheimer parece desconsiderar o que diz Dewey quando afirma que "as formas lógicas vêm ao objeto quando este é posto sob a investigação controlada" (DEWEY, 1980, p.55). Neste aspecto, o pragmatismo termina por se aproximar muito mais de Nietzsche, em Verdade e mentira no sentido extra-moral, e muito menos de Kant ao longo de suas críticas. É que, para Nietzsche, o homem quer a verdade, mas a verdade em um sentido restrito, pois:

Deseja as consequências da verdade que são agradáveis e conservam a vida; diante do conhecimento puro sem consequências ele é indiferente, diante das verdades talvez perniciosas e destrutivas ele tem disposição até mesmo hostil. (NIETZSCHE, 1987, p. 32 e 33)

Os pragmáticos terminam por realçar um certo "previsionismo" já implícito na filosofia de Nietzsche que, no entanto, é ignorado por Horkheimer em nome de uma verdade de âmbito mais geral. A afirmação de um juízo auto-evidente como fruto de uma intuição 
desinteressada poderia ser útil, por exemplo, para explicar o insucesso do ensino da álgebra e da geometria em nossas instituições de ensino, já que transmitidas como algo desinteressadas, pois não se pode pensar que a definição de um círculo veio de outro lugar senão de uma urgência prática, de uma necessidade de ação, e não que proveio de uma intuição de qualquer natureza, como que caída do céu.

Mas o ensaio de Horkheimer coloca instigantes e embaraçosas questões ao pragmatismo, questões de difíceis saídas e contornos, como, por exemplo, a de saber como é possível submeter a experimentação ao critério de "ser concebível" se qualquer conceito depende da experimentação? Aqui é como se o animal mordesse a própria calda. $\mathrm{O}$ embaraço consiste em reduzir tudo a simples conduta ou procedimento, pois se "a filosofia em seu estágio objetivista”, parafraseando o autor, procurou funcionar como a força que impulsionou a conduta humana e a sua produção (a techné), o pragmatismo reverte este processo tornando qualquer compreensão em simples conduta. O problema aqui é encontrar a zona de diferenciação entre teoria e prática, algo que a filosofia nunca quis abrir mão, deve-se ressaltar. É neste ponto que Horkheimer identifica o auge do anti-intelectualismo do pragmatismo, já que a consequência deste pensamento seria a dissolução de qualquer categoria intelectual em favor do desenrolar de acontecimentos. A resposta de Dewey seria que a análise é sempre física e ativa e "os significados em sua qualidade lógica são pontos de vista, atitudes e métodos de comportamento em relação aos fatos, e que a experimentação ativa é essencial à verificação" (HORKHEIMER, 2007, p.53). É curioso que Horkheimer ao mesmo tempo considere isto consistente, mas reivindique "o pensamento filosófico enquanto ainda é pensamento filosófico", deixando totalmente em aberto o que de fato seria este pensamento filosófico.

Outra contestação a ser notada no ensaio de Horkheimer diz respeito à fé de Dewey nos desejos das pessoas como as mais altas aspirações da humanidade. Ao realizar tal identificação, o autor estadunidense incorreria no erro de desconsiderar o derradeiro processo histórico de divisão de classes, divisão de trabalho, em suma, de reificação, não sendo, pois, aquilo que os homens desejam, eventualmente, a solução filosófica mais apropriada, podendo, inclusive, uma filosofia como esta considerar, na pior das hipóteses, a "solução final" como uma das aspirações de parte considerável da humanidade. Dewey parece se recusar a decidir por uma diferença entre desejo subjetivo e aspiração objetiva, o que o coloca em sérias dificuldades para realizar uma filosofia realmente crítica, enredando-se numa espécie de 
espírito antifilosófico que é, segundo o autor alemão, inseparável da dimensão subjetiva da razão.

\section{Conclusão}

As razões que levaram Horkheimer a atacar qualquer coisa ligada ao positivismo nos parecem legítimas e até mesmo justificadas, muito embora a ausência de rigor não seja algo que possa ser desconsiderado em filosofia. Horkheimer alude o insucesso da filosofia de James e Peirce ao período em que viveram. Para ele, os autores viveram numa época "em que a prosperidade e a harmonia [...] parecia prestes a ser alcançada" e que "a filosofia deles reflete, com uma sinceridade quase ingênua, o espírito comercial predominante, a própria atitude de 'ser prático' sendo algo em relação a que a meditação filosófica como tal era tida como oposta" (HORKHEIMER, 2007, p.57).

Nota-se, no conjunto da obra do autor de Frankfurt, uma enorme tensão com os desdobramentos da ciência e da técnica, sobretudo no que diz respeito à permanência da humanidade enquanto espécie sobre a terra. Não se pode negar o olhar estritamente europeu de suas linhas, mas também não se pode negar o poder irrefreável da técnica moderna enquanto poder bélico capaz de nos conduzir ao genocídio desde aqueles tempos. É importante ter em mente a data de seu texto: 1947. Naturalmente, Dewey viveu o suficiente para ver as duas grandes guerras, sem, no entanto, que seu ímpeto pragmático fosse refreado, mas, antes, ele foi se sofisticando com o passar dos anos. Por outro lado, de um judeu alemão, vítima da época sombria em que viveu, pode-se compreender a forma reativa como procedeu diante de uma filosofia que festejou o cálculo.

\section{NOTAS}

\footnotetext{
${ }^{1}$ Professor de Filosofia do Instituto Federal da Bahia (IFBA). Doutorando em Filosofia pela Universidade Federal da Bahia (UFBA). E-mail: roaraujo7@gmail.com.

${ }^{2}$ Cf. JAMES, W. "Pragmatismo" In Col. Os Pensadores, Tradução: Jorge Caetano da Silva, São Paulo: Abril Cultural, 1979.

${ }^{3}$ Cf. STEBBING, Susan, Pragmatism and French Voluntarism: With especial reference to the notion of truth in the development of French philosophy from Maine de Biran to Professor Bergson, Cambridge, University Press, 1914.
}

\section{REFERÊNCIAS BIBLIOGRÁFICAS}

DEWEY. J. "Lógica - A teoria da investigação" In Col Os Pensadores. Tradução de Murilo Otavio Rodrigues Paes Leme, São Paulo: Abril Cultural, 1980. 
HORKHEIMER. M. Eclipse da razão. Tradução de Sebastião Uchoa Leite, Rio de Janeiro: Labor do Brasil, 2007.

JAMES, W. "Pragmatismo" In Col. Os Pensadores. Tradução: Jorge Caetano da Silva, São Paulo: Abril Cultural, 1979.

NIETZSCHE, F. "Verdade e mentira no sentido extra-moral" In Col "Os Pensadores. Tradução de Rubens Rodrigues Torres Filho, $4^{\mathrm{a}}$ ed. São Paulo: Abril Cultural, 1987,”.

STEBBING, Susan, Pragmatism and French Voluntarism: With especial reference to the notion of truth in the development of French philosophy from Maine de Biran to Professor Bergson, Cambridge, University Press, 1914. 